\title{
Five-axis CNC Programming and Machining Simulation of the Integral Impeller
}

\author{
Yaoman Zhang ${ }^{1, a}$, Lili LI ${ }^{1, b}$, Fengjuan Dong ${ }^{2, c}$ \\ ${ }^{1}$ School of Mechanical Engineering \& Automation, Northeastern University, Shenyang, Liaoning \\ 110819, P.R. China \\ ${ }^{2}$ Automobile Design and Research Institute of Shandong Wuzheng Group, Rizhao, Shandong \\ 276800 P.R. China \\ azhangyaoman@mail.neu.edu.cn, b1538990641@qq.com, c1360595092@qq.com
}

\begin{abstract}
Keywords: Integral impeller; Five-axis CNC machining; Post-processing algorithm; Process planning; machining simulation

Abstract. Five-axis CNC machining has been widely used in complex parts with free-form surfaces. An integral impeller is taken as the research object of the paper. First, the NC machining process and cutter path planning of the integral impeller are studied; Second, the post-processing algorithm of the five-axis turn-milling machining center is studied and the corresponding post-processors are constructed, and the cutter path program of the integral impeller are generated; Finally, Five-axis turn-milling machining center model is designed for machining simulation, and the whole machining of the integral impeller is simulated and analyzed.
\end{abstract}

\section{Introduction}

Integral impeller is a kind of complex part with highly curved surfaces, it is widely used in the fields of aerospace, marine, energy etc[1]. Meanwhile, it is also the key component of the aircraft engine and the compressor impeller[2]. Besides, impeller's machining precision and quality have important influence on its mechanical properties, so it is required higher requirements for the impeller's design and processing.

The technology innovation of Five-axis NC machining has attracted more and more attention in recent years[3]. Integral impeller blades are usually formed by free-form surfaces, Five-axis NC machining is one of the most advanced methods for parts with free curved surfaces[4].

Cutter path planning is one crucial step in the integral impellers' machining. Much meaningful research about the cutter path planning of the integral impeller has been done by many scholars at home and abroad. Q.X. Zou studied integral impeller's cutter-path planning of the five-axis NC machining on the basis of the least squares principle, the finishing quality of the blade's surface was improved significantly[5]; X.Y. Li studied cutter-path generation of the blade's finishing based on the equal residues height, cutter pose angle and path interval algorithm, and implemented corresponding algorithm[6]; S.F. Wang developed special plunge milling rough machining programming module of the half-open integral impeller, the module could generate cutter-path automatically and realize computer-aided programming[7]. H.T. Young, L.C. Chuang et al. Studied rough machining cutter path planning algorithm of the centrifugal impeller, the processing time and cost was greatly reduced[8]; P. Lim optimized the integral impeller rough cutting parameters of Five-axis NC machining with response surface methodology to improve production efficiency significantly[9]; F.Y. Han, D.H. Zhang et al. studied cutters selection and cutter path optimization of impeller passage's multi-axis NC roughing, and machining efficiency was improved by 40\%[10]. W. Anotaipaiboon, S. Makhanov put forward the concept of generating Five-axis NC machining cutter-path by space adaptive curves, which minimized tool tilting angle and avoided scratching [11].

Above domestic and foreign scholars studied cutter-path generation of the integral impeller from different angles, beneficial references were provided for the tool-path planning of the integral impeller, but rarely involved in roughing programming method of dividing impeller passages into areas. Refer to former scholars theory and methods, this paper mainly studies cutter-path generation of the impeller 
flow channel, post-processing algorithm and post-processor generation, the generation of cutter-path program and machining simulation of the integral impeller. First, the rough machining programming method of dividing one impeller passage into three areas and machining them respectively is adopted, which can be a general reference for machining impellers. Then, the cutter-path program is generated by post-processor. At last, the machining simulation is conducted to verify the post-processor and cutter path program.

\section{Processing object and adopted machine tool}

The research object is turbine integral impeller with 8 long blades and 8 short blades, impeller diameter is $77 \mathrm{~mm}$, height is $43 \mathrm{~mm}$, blade thickness is $0.8 \mathrm{~mm}$, minimum distance between adjacent long blade and short blade is $4 \mathrm{~mm}$, the blade root fillet radius is $1 \mathrm{~mm}$.

HTM40100h Five-axis horizontal turn-milling machining center is adopted with two rotary axes of $\mathrm{B}$ and $\mathrm{C}$ besides $\mathrm{X}, \mathrm{Y}$ and $\mathrm{Z}$ axis, one is applied to worktable, another is for cutting tool, the rotation range of $\mathrm{B}$ and $\mathrm{C}$ axis is from $-120^{\circ}$ to $120^{\circ}$ and from $-360^{\circ}$ to $360^{\circ}$ respectively. It has obvious process-centralized advantage, it can not only complete all the processes in one clamping, but also can realize impellers' batch-machining by sawing, automatically feeding etc. Therefore, HTM40100h Five-axis turn-milling machining center is adopted to machine the integral impeller, which provides beneficial reference for machining integral impellers.

\section{The post-processing theory model}

The initial state of machine coordinate system is shown in Fig.1, cutter axis is perpendicular to $\mathrm{Z}$ axis, the working coordinate system is the same as machine coordinate system, the cutter and working coordinate system share the same original point[12].

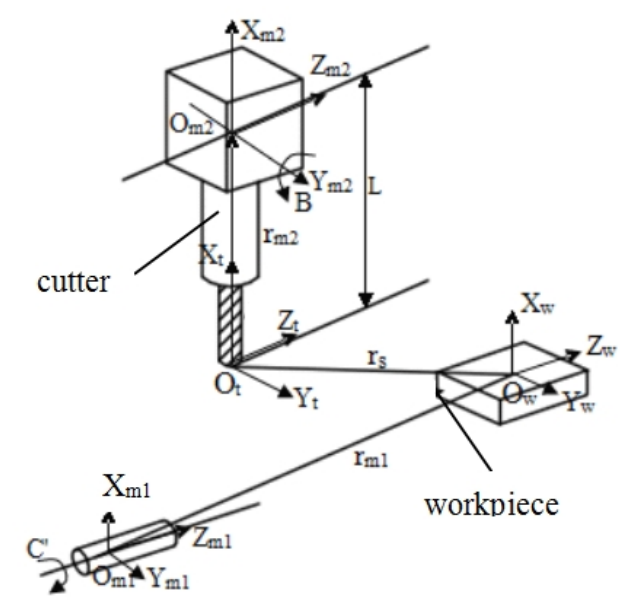

Fig.1 B-C structure coordinate system of the machine tool

$O_{w} X_{w} Y_{w} Z_{w}$ is supposed as working coordinate system and is combined with workpiece, front cutter location data is given by this coordinate system; $O_{t} X_{t} Y_{t} Z_{t}$ is cutter axis coordinate system, its origin point is set at cutter location point, its coordinate axis direction is the same as the machine coordinate system; $O_{m 1} X_{m 1} Y_{m 1} Z_{m 1}$ is the coordinate system coupled with $\mathrm{C}$ axis, its direction is the same as machine coordinate system, its original point $\mathrm{O}_{\mathrm{m} 1}$ can be freely chosen in the rotation axis line. $O_{m 2} X_{m 2} Y_{m 2} Z_{m 2}$ is the coordinate system that goes with $\mathrm{B}$ axis, its direction is the same as machine coordinate system, the origin point $\mathrm{O}_{\mathrm{m} 2}$ is the intersection of $\mathrm{B}$ axis and cutter axis.

The motion relationship is realized through the transformation of tool coordinate system $O_{t} X_{t} Y_{t} Z_{t}$ relative to workpiece coordinate system $O_{w} X_{w} Y_{w} Z_{w}$, can be further decomposed into the rotation of $O_{t} X_{t} Y_{t} Z_{t}$ relative to $O_{m 2} X_{m 2} Y_{m 2} Z_{m 2}$ and $O_{m 1} X_{m 1} Y_{m 1} Z_{m 1}$ relative to $O_{w} X_{w} Z_{w}$ respectively.

The angle calculation of $B$ and $C$ axis. According to angle calculation method of double turntable 
and double pendulum head, the following equations can be achieved:

$$
\begin{aligned}
& \begin{cases}\theta_{B}=0 & u_{z} \\
\theta_{B}=k \cdot \pi-n \cdot \arcsin \left(u_{z}\right) & u_{z} \neq 0 ; k=0, n=1 \quad \text { or } k=\frac{\arcsin \left(u_{z}\right)}{\left|\arcsin \left(u_{z}\right)\right|}, n=-1\end{cases} \\
& \begin{cases}\theta_{c}=k \cdot \pi-a c \tan \left(u_{y} / u_{z}\right) & u_{y} \neq 0 \text { and } u_{z} \neq 0 ; k= \pm 1,0 \\
\theta_{c}=0 & u_{z}=0 \text { and } u_{z}=0 \\
\theta_{c}=k \cdot \pi / 2 & u_{z}=0 \text { and } u_{y} \neq 0 ; k= \pm 1\end{cases}
\end{aligned}
$$

$\mathbf{x}, \mathbf{y}, \mathbf{z}$ coordinate calculation. The following equations can be achieved through the rotation of $O_{t} X_{t} Y_{t} Z_{t}$ relative to $O_{m 2} X_{m 2} Y_{m 2} Z_{m 2}$ and $O_{m 1} X_{m 1} Y_{m 1} Z_{m 1}$ relative to $O_{w} X_{w} Y_{w} Z_{w}$ respectively and the translation of $O_{m 2} X_{m 2} Y_{m 2} Z_{m 2}$ relative to $O_{m 1} X_{m 1} Y_{m 1} Z_{m 1}$ :

$$
\begin{aligned}
& {\left[\begin{array}{llll}
p_{x} & p_{y} & p_{z} & 0
\end{array}\right]^{T}=T\left(r_{m 1}\right) R_{Z}\left(-\theta_{C}\right) T\left(r_{s}-r_{m 1}+r_{m 2}\right) R_{Y}\left(\theta_{B}\right) T\left(-r_{m 1}\right)\left[\begin{array}{llll}
0 & 0 & 0 & 1
\end{array}\right]^{T}} \\
& {\left[\begin{array}{llll}
u_{x} & u_{y} & u_{z} & 0
\end{array}\right]^{T}=T\left(r_{m 1}\right) R_{Z}\left(-\theta_{C}\right) T\left(r_{s}-r_{m 1}+r_{m 2}\right) R_{Y}\left(\theta_{B}\right) T\left(-r_{m 2}\right)\left[\begin{array}{llll}
0 & 0 & 1 & 0
\end{array}\right]^{T}}
\end{aligned}
$$

In Eq. 3 and Eq.4, $\mathrm{T}$ and $\mathrm{R}$ are homogeneous transformation matrices of translation motion and rotary motion respectively, $u\left(u_{x} u_{y} u_{z}\right)$ and $p\left(p_{x} \quad p_{y} \quad p_{z}\right)$ are the cutter axis direction and cutter position vector of workpiece coordinate system.

The movement transformation relationship of machine tool can be achieved by substituting Eq.3 and Eq.4 into Eq.1 and Eq.2:

$$
\begin{aligned}
& {\left[\begin{array}{l}
u_{x} \\
u_{y} \\
u_{z} \\
0
\end{array}\right]=\left[\begin{array}{c}
\cos \left(\theta_{C}\right) \cdot \cos \left(\theta_{B}\right) \\
-\sin \left(\theta_{C}\right) \cdot \cos \left(\theta_{B}\right) \\
-\sin \left(\theta_{B}\right) \\
0
\end{array}\right]} \\
& {\left[\begin{array}{l}
p_{x} \\
p_{y} \\
p_{z} \\
1
\end{array}\right]=\left[\begin{array}{c}
-\cos \left(\theta_{C}\right) \cdot \cos \left(\theta_{B}\right) \cdot L+\cos \left(\theta_{C}\right) \cdot\left(s_{x}-m_{y}+L\right)+\sin \left(\theta_{C}\right) \cdot\left(s_{y}-m_{y}\right)+m_{x} \\
\sin \left(\theta_{C}\right) \cdot \cos \left(\theta_{B}\right) \cdot L-\sin \left(\theta_{C}\right) \cdot\left(s_{x}-m_{y}+L\right)+\cos \left(\theta_{C}\right) \cdot\left(s_{y}-m_{y}\right)+m_{y} \\
\sin \left(\theta_{B}\right) \cdot L+s_{z}-m_{z} \\
1
\end{array}\right]}
\end{aligned}
$$

The component motion of each axis can be calculated by the fusion of above equations:

$$
\left\{\begin{array}{l}
X=m_{x}-L-\sin \left(\theta_{c}\right) \cdot\left(p_{y}-m_{y}\right)+\cos \left(\theta_{c}\right) \cdot\left(p_{x}-m_{x}\right) \\
Y=m_{y}+\cos \left(\theta_{c}\right) \cdot\left(p_{y}-m_{y}\right)+\sin \left(\theta_{c}\right) \cdot\left(p_{x}-m_{x}\right) \\
Z=m_{z}-\sin \left(\theta_{B}\right) \cdot L+p_{z}
\end{array}\right.
$$

Theoretical basis is provided for constructing post-processor by above post-processing algorithm. In this paper, post-processors are generated based on the above post-processing algorithm, which make it ready for the generation of cutter-path program.

\section{Cutter-path program generation of the integral impeller}

According to Five-axis NC machining requirements of the integral impeller and machining characteristics of turn-milling machining center, refer to the mechanical machining process manual, recommended selection range of cutting parameter when aluminum alloy is cut by cemented carbide tool and detailed cutter dimension parameters, the CNC machining process can be achieved and is shown in table 1 .

The rough machining programming method adopted in this paper is to divide the impeller passage 
into three areas and process them respectively. These divided areas are shown in Fig.2.

When rough machining a area, the bottom surface is chosen as the driving mode because of its larger area range and smaller space variation, "Relative to driver" is chosen as cutter axis vector in UG, the cutter-path can be better by adjusting side rake angle. The cutter-path of a area is shown in Fig.3.

Table 1 The machining process of the integral impeller

\begin{tabular}{|c|c|c|c|c|c|c|c|}
\hline \multicolumn{2}{|c|}{ Tool material } & \multicolumn{2}{|c|}{ Cemented carbide } & \multicolumn{2}{|c|}{ Machining system } & \multicolumn{2}{|c|}{ SINUMERIK 840D } \\
\hline $\begin{array}{l}\text { Process } \\
\text { number }\end{array}$ & $\begin{array}{l}\text { Process } \\
\text { content } \\
\end{array}$ & $\begin{array}{c}\text { Cutter } \\
\text { number }\end{array}$ & Cutter pattem & $\begin{array}{c}\text { Spindle speed } \\
(\mathrm{r} / \mathrm{min})\end{array}$ & $\begin{array}{c}\text { Feed per tooth } \\
(\mathrm{mm})\end{array}$ & $\begin{array}{c}\text { Cutting } \\
\text { depth }(\mathrm{mm})\end{array}$ & $\begin{array}{l}\text { Cutting width } \\
(\mathrm{mm})\end{array}$ \\
\hline 1 & Face cutting & T1 & Tuming tool & 540 & 0.5 & 2 & 1 \\
\hline 2 & $\begin{array}{l}\text { Rough turning } \\
\text { outside contour }\end{array}$ & $\mathrm{T} 1$ & Turning tool & 350 & 0.5 & 2.5 & l \\
\hline 3 & $\begin{array}{l}\text { Finish turning } \\
\text { outside contour }\end{array}$ & $\mathrm{T} 2$ & Turning tool & 540 & 0.3 & 1 & / \\
\hline 4 & $\begin{array}{l}\text { Processing } \\
\text { through-hole }\end{array}$ & $\mathrm{T} 3$ & Drilling tool & 240 & 0.35 & 2 & / \\
\hline 5 & $\begin{array}{l}\text { Fine boring } \\
\text { through-hole }\end{array}$ & $\mathrm{T} 4$ & Tuming tool & 400 & 0.2 & 0.5 & / \\
\hline 6 & $\begin{array}{l}\text { Rough machining } \\
\text { flow pass }\end{array}$ & T5 & $\begin{array}{l}\text { Ball milling } \\
\text { tool }\end{array}$ & 3500 & 0.2 & 1 & 2 \\
\hline 7 & $\begin{array}{l}\text { Finishing } \\
\text { flow pass }\end{array}$ & T6 & $\begin{array}{l}\text { Ball milling } \\
\text { tool }\end{array}$ & 6000 & 0.1 & 0.2 & 1 \\
\hline 8 & Semi-finishing blades & T5 & $\begin{array}{l}\text { Ball milling } \\
\text { tool }\end{array}$ & 4000 & 0.15 & 0.5 & 1.5 \\
\hline 9 & Finishing blades & T6 & $\begin{array}{l}\text { Ball milling } \\
\text { tool }\end{array}$ & 6000 & 0.1 & 0.2 & 1 \\
\hline 10 & Finishing blade root & $\mathrm{T} 7$ & $\begin{array}{l}\text { Ball milling } \\
\text { tool }\end{array}$ & 6000 & 0.1 & 0.2 & 0.5 \\
\hline
\end{tabular}

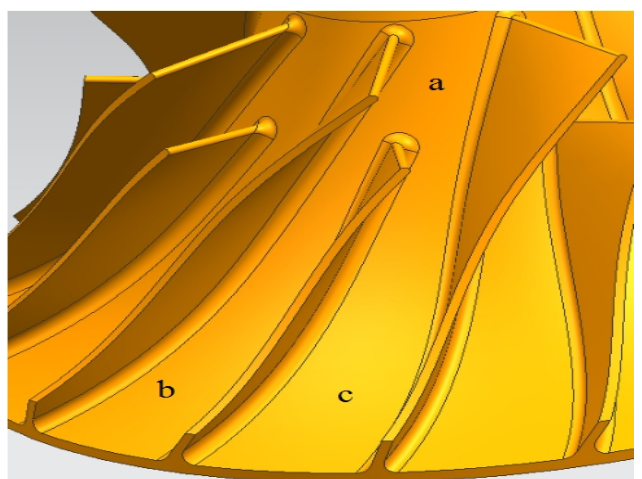

Fig.2 Divided areas

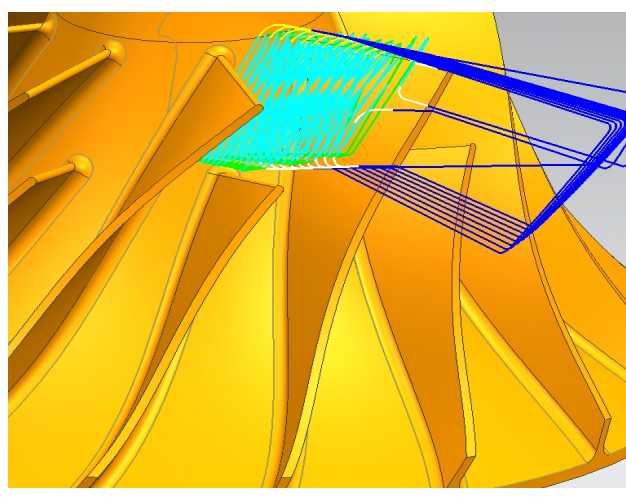

Fig. 3 The cutter-path of a area

Some guides, which are used for selecting cutter-axis vector, should be created before rough machining $b$ area, equal parameters curves should be inserted as many as possible because of bigger torsion resistance of blades. The Cutter-path of $\mathrm{b}$ area is shown in Fig.4.
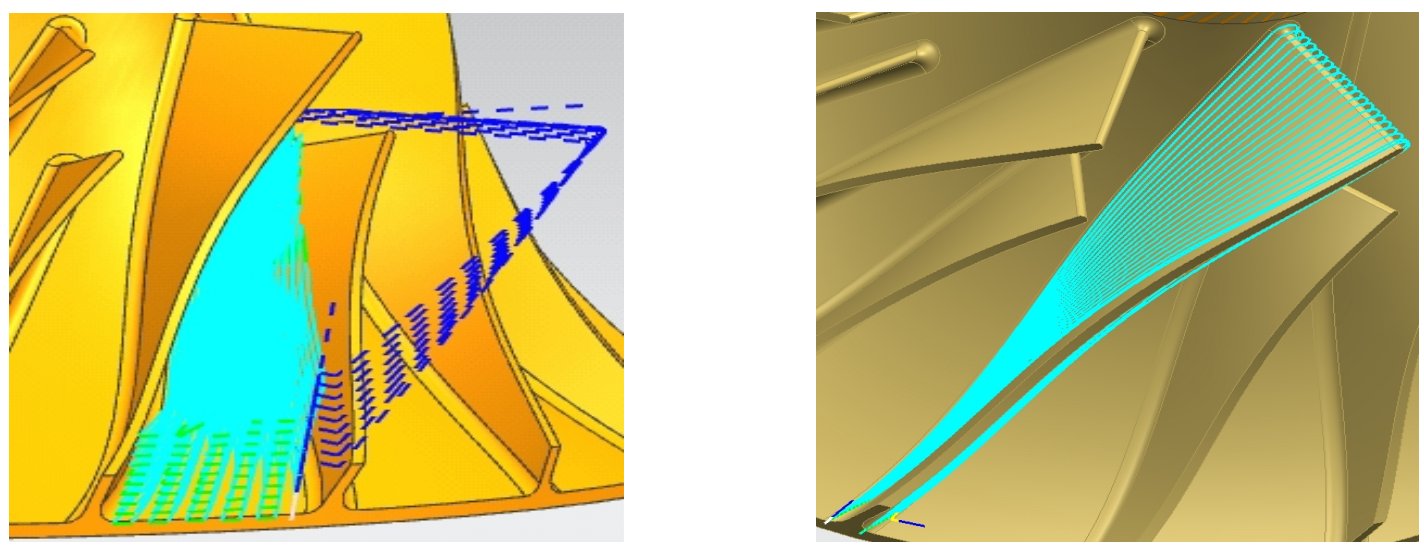

Fig.4 The cutter path of $\mathrm{b}$ area Fig.5 The semi-finish machining cutter-path of long blade The rough machining method of $c$ area is the same as that of $b$ area. When the single cutter-path of 
$\mathrm{a}, \mathrm{b}$ and $\mathrm{c}$ areas are finished, all the cutter-path of $\mathrm{a}, \mathrm{b}$ and $\mathrm{c}$ areas can be generated through "object-transformation" in UG.

During establishing the semi-finishing cutter-path of the long blade, the blade surface is chosen as driving mode, "side edge driving body" is chosen to control cutter axis in UG. Proper side rake angle is set to avoid the collision of cutter axis and geometry. The semi-finishing cutter-path of the long blade is shown in Fig.5. The semi-finishing programming method of short blades is the same as that of long blades. The same method can be adopted to generate finish machining cutter-path of long and short blades by changing cutting parameters. Exclusive programming module of impellers in UG can be used to generate the rest program of the integral impeller.

\section{The machining simulation and analysis of the integral impeller}

In order to verify the program and post-processors of the integral impeller, it is very necessary to simulate and analyze cutter-path program of the integral impeller.

First, the Five-axis turn-milling machining center need to be constructed for machining simulation. Based on the existing assembly model of the turn-milling machining center, deleting unnecessary parts and geometric features, the necessary modules are kept and saved as *.stl files. Then all the *.stl files are imported into VERICUT, according to the project tree, machine tool and component coordinate system, the machine tool is assembled, the assembly model is shown in Fig.6. Thirdly, corresponding tool library is established, and the program are also imported into VERICUT etc. Finally, the machining simulation result is shown in Fig.7. The simulation result and design model are also compared and analyzed and the result is shown in Fig.8.

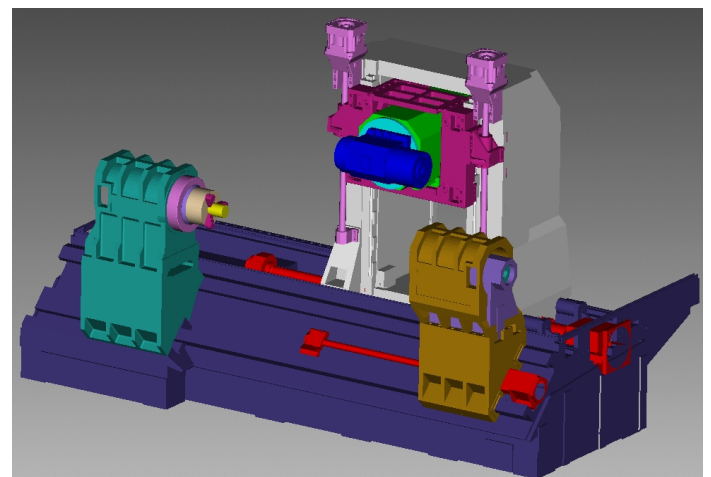

Fig.6 The assembly model of machine tool

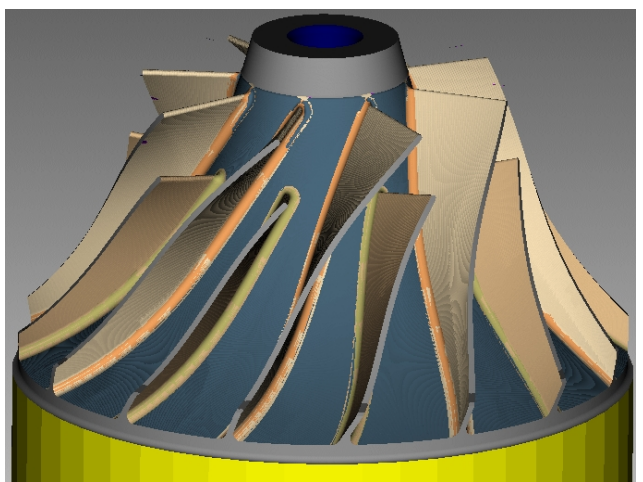

Fig.7 The result of machining simulation

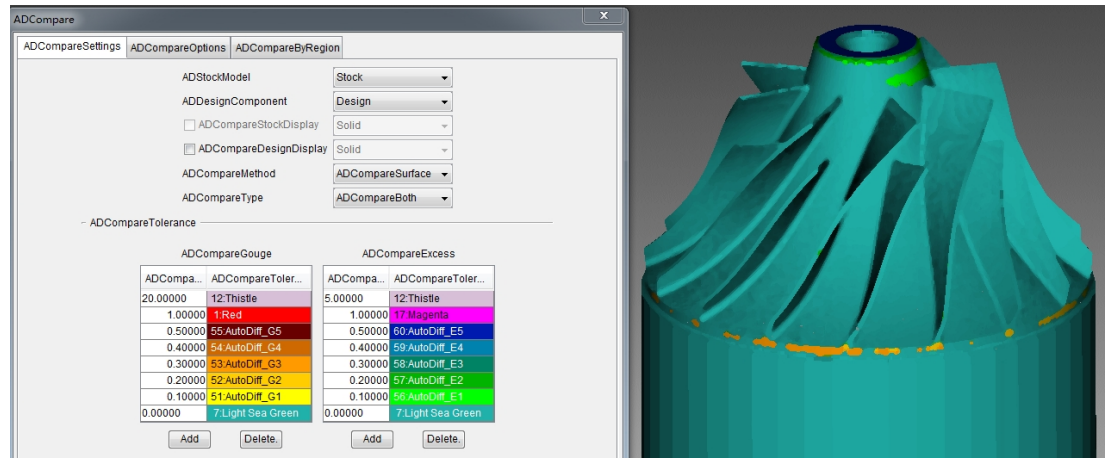

Fig. 8 The comparative method and result

By means of comparing and analyzing the simulation result of impeller in VERICUT, the report can be gotten: one over-cutting of $0.045 \mathrm{~mm}$ and the maximum residual is $0.56 \mathrm{~mm}$ with the number of 30. Over-cutting quantity is within permitted scope, but the residual, which is mainly distributed in turning region, can be reduced by turning again. After secondary machining, the maximum residue is $0.12 \mathrm{~mm}$ with the number of 8 , compared with former simulation result, machining result have been improved greatly. 


\section{Conclusions}

The post-processing algorithm is studied firstly in this paper, and corresponding post-processors are constructed. Then programs of the integral impeller are generated. At last, the geometry simulation of the integral impeller is completed, and the validity and availability of the program and post-processors are demonstrated. Conclusions are shown as follows:

(1) The over-cutting problem during the machining is solved by modifying the cutter-path program and setting up suitable cutter axis vector. The collision of cutter and workpiece is settled through turning the cut-in and cut-out pattern into smooth connection with suitable smoothing parameters.

(2) The "curve fitting" in VERICUT is used for the program, the linear motion number of the same line is reduced, the program is shorted and the machining efficiency is improved.

(3) The secondary cutting is adopted for residual areas. Small size cutter is used for the secondary machining small area surface, as a result, the data self- agreement is increased to 95\%, while residual amount is decreased by $73 \%$ with maximum residue of $0.12 \mathrm{~mm}$, the machining quality is improved significantly.

\section{Acknowledgements}

This work was financially supported by the National Natural Science Foundation of China(51575092) and the Fundamental Research Funds for the Central Universities(N140104001) and Project of Education Department of Liaoning Province(L20150184).

\section{References}

[1] Maoyue Li, Xianli Liu, Dongka Jia. Proceedings of the Institution of Mechanical Engineers Part B-Journal of Engineering Manufacture, 2015, 07, 229(7): 1118-1130.

[2] Qiong Wu, Yidu Zhang, Hongwei Zhang. Chinese Journal of Aeronautics, 2012, 10, 25(5): 804-810.

[3] Han Ding, Qingzhen Bi, Limin Zhu. Chinese Science Bulletin, 2010,10, 55(30):3408-3418.

[4] Lin Than, Lee Jae-Woo, Bohez Erik L.J. Journal of Mechanical Science and Technology, 2009, 10, 23(10): 2624-2634.

[5] Qixiao Zou. Research in tool path planning method based on the least squares principle of impeller machining[D]. Dalian Science\&Engineering University,2015. In Chinese.

[6] Xianyi Li. Research in tool path planning and implementation technology without interference for five-axis machining of impeller[D]. Zhejiang university, 2012. In Chinese.

[7] Shengfu Wang. Research in NC plunge-milling machining tool path planning of half open integrate impeller[D]. Dalian Science \& Engineering University, 2014.In Chinese.

[8] H.-T.Young, L.-C.Chuang, K. Gerschwiler S. Kamps. Int J Adv Manuf Technol,2004(23):233239.

[9] Pyo Lim. Int J Adv Manuf Technol, 2009(45): 821-829.

[10] F. Y. Han, D. H. Zhang, M. Luo, B. H.Wu. Int J Adv Manuf Technol, 2014(71): 1801-1810.

[11] Anotaipaiboon, W, Makhanov, SS. International Journal of Production Research, 2005, 4, 43(8): 1643-1665.

[12] Ruirui Qu. Combination machine tool and automatic machining technology. 2013, 9(9): 118-120. In Chinese. 